\title{
Corporate tools for public policy: stakeholders views and beliefs about the use of nutrition and health claims on food products
}

\author{
A. Allard ${ }^{1}$, M. Dean ${ }^{1}$ and M. M. Raats ${ }^{2}$ \\ ${ }^{1}$ Institute of Agri-Food \& Land Use. Queens University Belfast, Belfast BT9 5AG, UK and ${ }^{2}$ Food Consumer Behaviour and \\ Health Research Centre, University of Surrey, Guilford GU2 7XH, UK
}

In recent years, nutrition science has progressed from a concept of adequate nutrition to one of optimal nutrition where emphasis is placed on the potential for foods to improve health and well-being. Therefore, health messages on food have been conceptualised in the policy discourse as an essential element in improving public health ${ }^{(1)}$.

In 2001, the European Commission prepared a Discussion Paper outlining the issues that needed to be considered in relation to the harmonisation of the various approaches governing the use of Nutrition and Health $(\mathrm{NH})$ claims across Member States ${ }^{(2)}$. During the consultation process, 67 official replies were received from various stakeholders. The aim of the present qualitative study was to identify the extent to which the use of NH claims was viewed as a science-based strategy to improve public health by these stakeholders. Based on the Advocacy Coalition Framework's tenets about the structure of individual beliefs and motivation to influence policy ${ }^{(3)}$, a conceptual analysis of the 67 official replies was conducted.

The analysis identified two main core beliefs strands which segregated the stakeholders into two distinct advocacy coalitions. The first coalition (C1) was composed of consumer organisations and some health professionals ( $n$ 21) who believed that the concept behind NH claims was running counter to existing dietary recommendations and blurring the lines between food and medicine. They also believed that any potential benefits associated with the use of $\mathrm{NH}$ claims were largely outweighed by their potential to mislead and confuse consumers. By contrast, the second coalition (C2) was composed of food companies, some food scientists and some regulators (n 39) who believed that the use of $\mathrm{NH}$ claims on food products was in line with current thinking on the promotion of public health through greater information on healthy eating. Further analysis of the stakeholders' replies suggests that concurrent events in other venues, like the Ribena ToothKind Court case, may have influenced the stakeholders' contribution to the consultation process.

The present study provides evidence that the use of $\mathrm{NH}$ claims as a science-based strategy to improve public health was contested within the policy discourse. Indeed, many civil society stakeholders viewed the use of NH claims as an elaborate marketing strategy to serve commercial interests.

1. Diplock AT et al. (1999) Br J Nutr 81, S1-S27.

2. Sanco DG (2001) Discussion Paper on Nutrition and Functional Claims. http://ec.europa.eu/food/fs/fl/fl03_en.pdf

3. Weible MC (2006) J Part 17, 95-177. 